\title{
The Research of Metering Well Yield Technology Based on Dynamometer Card
}

\author{
Tao Ren ${ }^{\mathrm{a}}$, Cheng Sun, Wen Sun , and Xiaoqing Kang \\ School of Mechanical Engineering, Xi'an Shiyou University, Shaanxi, Xi'an,710065, P.R.China \\ a rentao365@126.com,
}

Keywords: dynamometer card; effective stroke; calculation model; production measurement

\begin{abstract}
At present, the main method of metering oil well output is transporting all oil to the metering station for centralized measurement in china oil fields, but it is hard to meet the requirements of ground system in convenience, simple and relative reliability. Therefore, an crude oil metering technology which needs no ground station, costs low engineering investment and can satisfy requirements of continuous real-time automatic measurement is cried for. The output metering technology based on dynamometer card was put forward to solve the problem of single well yield metering. The surface dynamometer card is used as boundary conditions to establish the one-dimensional wave equation which is based on rod string. Draw the corresponding downhole pump card by solving the equation, and extract the effective stroke from pump card. The pump output finally will be calculated consequently.
\end{abstract}

\section{Introduction}

In the oil pumping well system, the well yield measurement is an important work in the production management, metering oil well`s production timely and effectively is of great practical significance for mastering reservoir condition and optimizing production scheme. At present, the main method of measuring well yield is transporting all wells` oil to the metering station for centralized metering [1] in china oilfields. Principal measurement method includes glass-tube metering, dump metering and three-phase metering etc [2]. The problems are widespread in these methods, such as overfull applica -tion device, complex technology process and so on. These methods are difficult to meet the require -ments of the ground system`s metering accuracy. In addition, china`s vast territory and dispersed wells, these methods seem very uneconomical for scattered and remote wells. Therefore, we need an oil well production measurement technique no ground station, low engineering cost and can satisfy requirements of continuous and real-time to be the main metering method to take the place of the present metering station. With the development of diagnostic technology based on dynamometer card, it provides the basis for the dynamometer card measurement technology.

\section{The dynamic model of rod string}

S.G.Gibbs developed diagnosis analysis technology and established a rod string system of one-dimensional viscous damping wave equation, using the approach of variable separation obtains its approximate solution with truncated Fourier series. The boundary conditions are ground dynamometer card`s load - displacement and displacement - time curves [3]. This method can obtain rod string arbitrary cross-section and pump card.

Rod string motion and stress propagation`s viscous damping wave equation [3]:

$$
\frac{\partial^{2} u(x, t)}{\partial t^{2}}=a^{2} \frac{\partial^{2} u(x, t)}{\partial x^{2}}-c \frac{\partial u(x, t)}{\partial t}
$$

The polished rod dynamic load function and the suspension point displacement function expressed by the truncated Fourier series [4] 
$\left\{\begin{array}{l}\mathrm{D}(\mathrm{t})=\mathrm{W}(\omega \mathrm{t})-\mathrm{W}_{\mathrm{r}}=\frac{\sigma_{0}}{2}+\sum_{\mathrm{n}=1}^{\mathrm{n}}\left(\sigma_{\mathrm{n}} \cos \mathrm{n} \omega \mathrm{t}+\tau_{\mathrm{n}} \sin \mathrm{n} \omega \mathrm{t}\right) \\ \mathrm{u}(\mathrm{t})=\frac{\gamma_{0}}{2}+\sum_{\mathrm{n}=1}^{\mathrm{n}}\left(\gamma_{\mathrm{n}} \cos \mathrm{n} \omega \mathrm{t}+\delta_{\mathrm{n}} \sin \mathrm{n} \omega \mathrm{t}\right)\end{array}\right.$

The Fourier coefficients are confirmed by follows:

$\left\{\begin{array}{lc}\sigma_{n}=\frac{T}{2} \int_{0}^{T} D(t) \cos \omega t d t & n=0,1,2, \cdots \bar{n} \\ \tau_{n}=\frac{T}{2} \int_{0}^{T} D(t) \sin \omega t d t & n=0,1,2, \cdots \bar{n} \\ \gamma_{n}=\frac{T}{2} \int_{0}^{T} u(t) \cos \omega t d t & n=0,1,2, \cdots \bar{n} \\ \delta_{n}=\frac{T}{2} \int_{0}^{T} u(t) \sin \omega t d t & n=0,1,2, \cdots \bar{n}\end{array}\right.$

The equations of displacement with time at rod string arbitrary depth`s x section [4]:

$\left\{\begin{array}{l}\mathrm{u}(\mathrm{x}, \mathrm{t})=\frac{\sigma_{0}}{2 \mathrm{EA}_{\mathrm{r}}}+\frac{\gamma_{0}}{2}+\sum_{\mathrm{n}=1}^{\mathrm{n}}\left(\mathrm{O}_{\mathrm{n}}(\mathrm{x}) \cos \mathrm{n} \omega \mathrm{t}+\mathrm{P}_{\mathrm{n}}(\mathrm{x}) \sin \mathrm{n} \omega \mathrm{t}\right) \\ \mathrm{F}(\mathrm{x}, \mathrm{t})=\frac{\sigma_{0}}{2}+\mathrm{EA}_{\mathrm{r}} \sum_{\mathrm{n}=1}^{\mathrm{n}}\left(\frac{\partial}{\partial \mathrm{x}} \mathrm{O}_{\mathrm{n}}(\mathrm{x}) \cos \mathrm{n} \omega \mathrm{t}+\frac{\partial}{\partial \mathrm{x}} \mathrm{P}_{\mathrm{n}}(\mathrm{x}) \sin \mathrm{n} \omega \mathrm{t}\right)\end{array}\right.$

$\left\{\begin{array}{l}\mathrm{O}_{\mathrm{n}}=\left(\mathrm{K}_{\mathrm{n}} \operatorname{ch} \beta_{\mathrm{n}} \mathrm{x}+\delta_{\mathrm{n}} \operatorname{sh} \beta_{\mathrm{n}} \mathrm{x}\right) \sin \alpha_{\mathrm{n}} \mathrm{x}+\left(\mathrm{u}_{\mathrm{n}} \operatorname{sh} \beta_{\mathrm{n}} \mathrm{x}+\gamma_{\mathrm{n}} \operatorname{ch} \beta_{\mathrm{n}} \mathrm{x}\right) \cos \alpha_{\mathrm{n}} \mathrm{x} \\ \mathrm{P}_{\mathrm{n}}=\left(\mathrm{K}_{\mathrm{n}} \operatorname{sh} \beta_{\mathrm{n}} \mathrm{x}+\delta_{\mathrm{n}} \operatorname{ch} \beta_{\mathrm{n}} \mathrm{x}\right) \cos \alpha_{\mathrm{n}} \mathrm{x}-\left(\mathrm{u}_{\mathrm{n}} \operatorname{ch} \beta_{\mathrm{n}} \mathrm{x}+\gamma_{\mathrm{n}} \operatorname{sh} \beta_{\mathrm{n}} \mathrm{x}\right) \sin \alpha_{\mathrm{n}} \mathrm{x}\end{array}\right.$

$\left\{\begin{array}{l}\alpha_{\mathrm{n}}=\frac{\mathrm{n} \omega}{\mathrm{a} \sqrt{2}} \sqrt{1+\sqrt{1+\left(\frac{\mathrm{c}}{\mathrm{n} \omega}\right)^{2}}} \quad \mathrm{n}=1,2, \cdots \\ \beta_{\mathrm{n}}=\frac{\mathrm{n} \omega}{\mathrm{a} \sqrt{2} \sqrt{-1+\sqrt{1+\left(\frac{\mathrm{c}}{\mathrm{n} \omega}\right)^{2}}}} \quad \mathrm{n}=1,2, \cdots \\ \mathrm{K}_{\mathrm{n}}=\frac{\sigma_{\mathrm{n}} \alpha_{\mathrm{n}}+\tau_{\mathrm{n}} \beta_{\mathrm{n}}}{\mathrm{EA}_{\mathrm{r}}\left(\alpha_{\mathrm{n}}^{2}+\beta_{\mathrm{n}}^{2}\right)} \\ \mu_{\mathrm{n}}=\frac{\sigma_{\mathrm{n}} \alpha_{\mathrm{n}}-\tau_{\mathrm{n}} \beta_{\mathrm{n}}}{\mathrm{EA}_{\mathrm{r}}\left(\alpha_{\mathrm{n}}^{2}+\beta_{\mathrm{n}}^{2}\right)}\end{array}\right.$

Where, $\mathrm{x}$ is any section depth $(\mathrm{m})$; $\mathrm{t}$ is time $(\mathrm{s})$; $\mathrm{a}$ is the propagation velocity of stress wave in rod string $(\mathrm{m} / \mathrm{s})$; $\mathrm{c}$ is the viscous damping factor $\left(\mathrm{s}^{-1}\right) ; \mathrm{D}(\mathrm{t})$ is the function between the suspension point load and time in polished $\operatorname{rod}(\mathrm{N})$; Wr is the rod string weight in well fluid $(\mathrm{N})$; $\mathrm{u}(\mathrm{t})$ is the function between the suspension point displacement and time in polished $\operatorname{rod}(\mathrm{m}) ; \mathrm{u}(\mathrm{x}, \mathrm{t})$ is the displacement function of rod string at $\mathrm{x}$ section in different time $(\mathrm{m}) ; \mathrm{F}(\mathrm{x}, \mathrm{t})$ is the load function of rod string at $\mathrm{x}$ section in different time $(\mathrm{N})$; $\mathrm{E}$ is the elastic modulus of rod string $\left(\mathrm{N} / \mathrm{m}^{2}\right)$; Ar is the sectional area of rod string $\left(\mathrm{m}^{2}\right)$; $\omega$ is the angular velocity of crank $(\mathrm{rad} / \mathrm{s}) ; \mathrm{n}$ is the number of terms of Fourier series.

\section{Pump output model}

The surface dynamometer card can be transformed into the pump card by using the S.G.Gibbs`s one-D viscous damping wave equation. The surface dynamometer card is shown in Figure 1, and pump card is shown in Figure 2.

The pump plunger effective stroke is the displacement difference from open point (point A) to close point (point $\mathrm{B}$ ). The effective stroke is:

$$
S_{A B}=\overline{A B}
$$




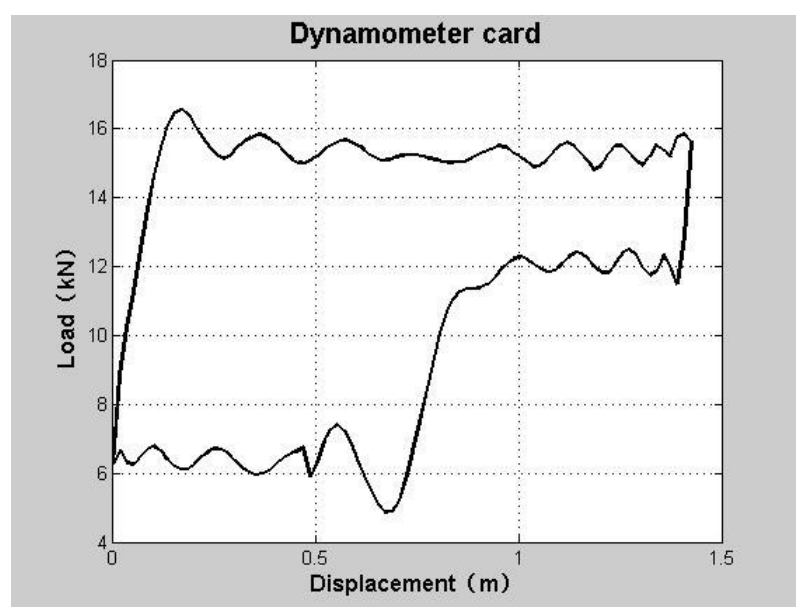

Fig. 1 dynamometer card

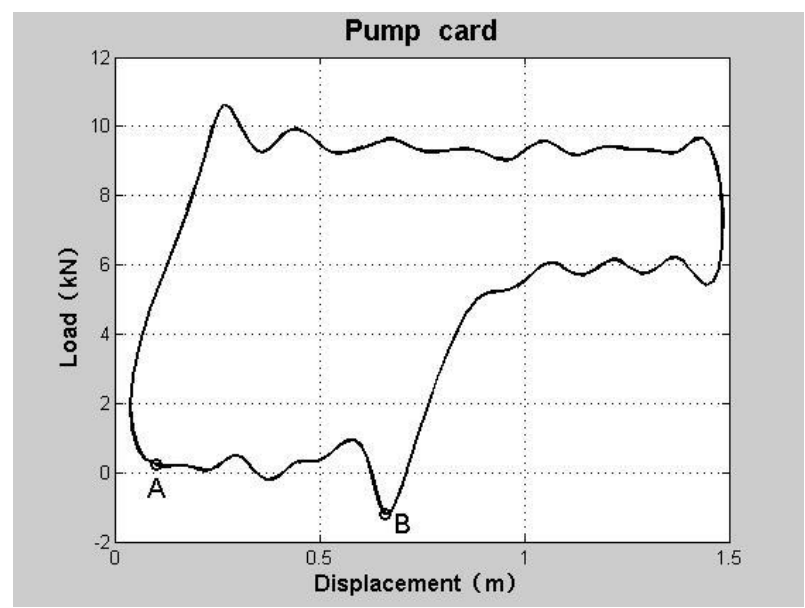

Fig. 2 pump card

Theoretical yield calculation model. When pump is full of water and oil, the amount of the mixture equals to the theoretical yield, assumed that the plunger`s effective stroke equals to the polished rod stroke. As calculation formula [3] shown:

$$
Q_{t}=1440 S N A_{p}
$$

Where, $\mathrm{S}$ is the stroke of polished $\operatorname{rod}(\mathrm{m}) ; \mathrm{N}$ is the pump speed $\left(\mathrm{min}^{-1}\right) ; \mathrm{A}_{\mathrm{p}}$ is the plunger sectional area $\left(\mathrm{m}^{2}\right)$.

Theoretical yield calculation model. The actual yield of oil well is the final ground production after the wellhead crude oil was degassed, it`s calculation formula is:

$$
Q_{t}=1440 S_{A B} N A_{p} \mu
$$

Where, $S_{\mathrm{AB}}$ is the plunger effective stroke $(\mathrm{m})$; $\mu$ is the volume factor of oil $\left(\mathrm{m}^{3} / \mathrm{m}^{3}\right)$.

(1)The volume factor of oil $\mu$

The volume factor of the mixture in pipe is the ratio of volumes of the liquid on ground and the mixed liquids in pipe under the condition of $(\mathrm{P}, \mathrm{T})$, it is related to pressure $\mathrm{P}$, temperature $\mathrm{T}$, dissolved gas oil ratio Rs, crude oil volume factor Bo, water volume factor $\mathrm{Bw}$ and other parameters. It is derived from the calculation as follows [5]:

$$
\mu=\frac{1}{\left(1-n_{w}\right) B_{o}+n_{w} B_{w}}
$$

Where, $\mathrm{n}_{\mathrm{w}}$ is the water content of the mixture under standard condition $(\%)$; $\mathrm{B}_{\mathrm{o}}$ is the volume factor of crude oil under down hole conditions $(\mathrm{P}, \mathrm{T})\left(\mathrm{m}^{3} / \mathrm{m}^{3}\right) ; \mathrm{B}_{\mathrm{w}}$ is the water volume factor under down hole condition $(\mathrm{P}, \mathrm{T})\left(\mathrm{m}^{3} / \mathrm{m}^{3}\right)$.

(2)The crude oil volume factor $B_{o}$

The crude oil volume factor $\mathrm{B}_{\mathrm{o}}$ is the ratio of volumes of the crude oil under the condition of $(\mathrm{P}, \mathrm{T})$ and the crude oil had degassed on the ground under standard condition, it can be calculated by the AL-Marhoun formula [5][6].

(3)The water volume factor $B_{w}$

The water volume factor $B_{w}$ is the ratio of volumes of the water at the outlet of pump and the water on the ground, it can be calculated by the next [5-6].

$$
B_{w}=C_{0}+145.03 p C_{1}+(145.03 p)^{2} C_{2}
$$

Where, $\mathrm{p}$ is the down hole pressure $(\mathrm{MPa}) ; \mathrm{C}_{0}, \mathrm{C}_{1}, \mathrm{C}_{2}$ are coefficients.

\section{Application example}

This paper takes the dynamometer card measurement algorithm into the calculation of production of oil wells in Yanchang oil field, and calculated the production of 5 wells which are named Chuan 5-1, Chuan 5-2, Chuan 5-zhi, Chuan 5-4, Chuan 5-5 respectively after collected their dynamometer cards, and compared the calculation results with the measured production. As shown in table 1. 
Table 1 The production of dynamometer card and measured

\begin{tabular}{|c|c|c|c|c|c|}
\hline Item & Chuan15-1 & Chuan 15-2 & Chuan 15-zhi & Chuan 15-4 & Chuan 15-5 \\
\hline $\begin{array}{c}\text { The production of } \\
\text { dynamometer card (t/d) }\end{array}$ & 0.85 & 0.97 & 0.76 & 1.02 & 1.25 \\
\hline Measured production (t/d) & 0.81 & 1.01 & 0.80 & 0.94 & 1.19 \\
\hline Relative error (\%) & 4.52 & -3.68 & -5.74 & 6.85 & 5.06 \\
\hline
\end{tabular}

The comparison data shows that the output calculated by the algorithm with the dynamometer card is basically able to meet the requirements of the oil field for the production measurement of oil well.

\section{Conclusions}

In this paper, based on the development of the diagnosis technology of the dynamometer card, the oil well output measurement model is established, which provides a convenient, simple and relatively reliable measurement method for the production of oil well. Compared analysis with the measured output, the measurement of the oil well output based on the dynamometer card has an extraordinary important practical significance to the oilfield.

\section{Acknowledgements}

The authors would like to thank the Shaanxi Science and Technology Innovation Scheme (2015KTZDGY06-02), Key Problems of Industrial Science and technology of Shaanxi Province (2015GY110), (2016GY-185) and the Local Service Scheme of Shaanxi Province Education Department (15JF027) for financial support.

\section{References}

[1] C.T. Jiang, Y.F. Zhu, L.D. Pan,Analysising of development trend and present situation of oil-gas measure technology in oilfield Internal,China Metrology Publishing House, Beijing,2006,pp. 15-16. [2] Q. Tang, Q.H. Wang, F.S Sun, et al, The pilot test of pumping diagram of metering oil technolo -gy,Wells Testing, 15 (2006)64-65.

[3] X.K. Chen, L.P. Ye, Y.H. Gu. Oil production technology of pumping unit ,Petroleum Industry Press, Beijing,2006.

[4] Z.H. Cui, G.A. Yu, J.G. An, Rod pumping system,Petroleum Industry Press, Beijing,1994, pp.270-280.

[5] S.M. Dong, X.H. Cui, A new method to calculate the full coefficient of the oil pump,Petroleum Machinery, 30(2002)37-39 .

[6] J.L. Chen, T.P. Chen. The pumping well`s gas-liquid two-phase Flow , Petroleum Industry Press, Beijing,1994, pp.175-180. 